\title{
PREVALENCE OF NEUROIMAGING ABNORMALITIES IN CHILDREN WITH NEW ONSET AFEBRILE SEIZURES IN TERTIARY CARE HOSPITAL
}

\author{
E. Ganga Bhavani1, T. V. Ramesh ${ }^{2}$
}

1 Junior Resident, Department of Paediatrics, GSL Medical College, Rajahmundry, Andhra Pradesh.

2 Professor and HOD, Department of Paediatrics, GSL Medical College, Rajahmundry, Andhra Pradesh.

\begin{abstract}
BACKGROUND

Seizures are the most common Paediatric neurological disorder with worldwide prevalence of 10.5 million children under 15 years have active seizures. The role of neuroimaging in children presenting with first non-febrile seizure is still not well-defined. The American Academy of Neurology states that these evidences are not sufficient to make a commendation at the level of guideline for the use of routine neuroimaging in children with a new-onset seizure. But in developing countries like India, where the incidence of CNS infections like neurocysticercosis and tuberculoma are common the data is insufficient about role of neuroimaging.
\end{abstract}

AIM

To know the prevalence of neuroradiological abnormalities in first episode of unprovoked afebrile seizures.

\section{MATERIALS AND METHODS}

This was a prospective study done over periods of 24 months involving 80 patients. The statistical analysis was performed by using SPSS-20 version and MS-Excel 2007.

\section{RESULTS}

Neuroimaging was performed in 80 patients, and abnormalities were found in $75 \%$ of cases and $25 \%$ were normal. Most common neuroimaging abnormality observed was NCC (49\%) followed by tuberculoma (23\%).

\section{CONCLUSION}

This study concludes that neuroimaging should be considered for even first episode of unprovoked seizures.

\section{KEYWORDS}

Unprovoked Seizures, Neuroimaging, Neurocysticercosis, Tuberculoma.

HOW TO CITE THIS ARTICLE: Bhavani EG, Ramesh TV. Prevalence of neuroimaging abnormalities in children with new onset afebrile seizures in tertiary care hospital. J. Evolution Med. Dent. Sci. 2016;5(48):3066-3069, DOI: 10.14260/jemds/2016/714

\section{INTRODUCTION}

Seizures are the most common Paediatric neurological disorder with 4 to $10 \%$ of children, who suffer at least one seizure in the first 16 years of life.(1) In the developing world, its onset is more common in older children and young adults due to the higher rates of trauma and infectious diseases. (2) Worldwide, it was estimated that 10.5 million children under 15 years have active seizures representing about $25 \%$ of the global seizure population. Of the 3.5 million people who develop seizures annually, $40 \%$ are younger than 15 years and more than $80 \%$ live in developing countries.(3) The seizure incidence rates reported from India were higher and reached 60.0 per 100000 person-years.(4) The role of neuroimaging in children presenting with first non-febrile seizure is still not well-defined. Based on several studies, the prevalence of abnormal neuroimaging in paediatric patients with a new-onset non-febrile seizure is estimated to be $0 \%$ to $21 \% .(5,6)$

Financial or Other, Competing Interest: None.

Submission 05-04-2016, Peer Review 30-04-2016,

Acceptance 05-05-2016, Published 15-06-2016.

Corresponding Author:

Dr. T. V. Ramesh,

Professor, Department of Paediatrics,

GSL Medical College,

Rajahmundry,

Andhra Pradesh.

E-mail: drtvr2010@gmail.com

DOI: $10.14260 /$ jemds/2016/714
There is lack of data that has looked at Neuroimaging in all children after a first afebrile, unprovoked seizure from developing countries, where the incidence of CNS infections are common and causes for an apparent unprovoked afebrile seizure may be different from Western World. The aim of our study is to know the prevalence of neuroradiological abnormalities in first unprovoked seizures in afebrile children.

\section{MATERIALS AND METHODS}

Children in the age group of 6 months to 16 years who presented to the Department of Paediatrics, GSL Hospital, with the symptoms of first episode of afebrile seizures were evaluated prospectively. Cases with first episode of afebrile seizures that came to Paediatrics Department during the period between September 2012 and July 2014 were taken (Sample- 80 patients). Detailed history was taken and seizures categorized according to the Classification proposed by International League Against Epilepsy (ILAE) 2006. Thorough clinical examination was performed to detect any abnormality in the nervous system. Diagnosis was verified by Neuroradiological tests (MRI).

Inclusion criteria is the $1^{\text {st }}$ episode of afebrile seizures, age group 6 months-16 years and exclusion criteria is past $\mathrm{h} / \mathrm{o}$ seizures, seizures with fever, meningitis, encephalitis, CNS malformations. Primary diagnosis other than seizures were excluded. The purpose of this study was explained to the parents/guardian and written consent was taken prior to the study. Permission was obtained from the Independent 
Ethical Committee of GSL Medical College before starting the study. The statistical analysis was performed by using SPSS20 version and MS Excel - 2007. Variables were reported as mean $\pm S D$. Chi-square test was performed to determine the correlation. $\mathrm{P}$ value of $<0.05$ was considered statistically significant.

\section{OBSERVATIONS AND RESULTS}

A total of 80 cases presented within one week of throwing seizures; $18(22.5 \%)$ cases were simple partial, $33(41.3 \%)$ cases were complex partial and $4(5 \%)$ cases were partial seizures with $2^{\circ}$ generalization, $25(31.3 \%)$ cases were generalized seizures respectively (Table 1). Maximum number of seizures presented in age group between 5-9 yrs. $38.8 \%(n=31)$ followed by $9-13$ yrs. $26.6 \%(n=21)$. (Figure 1$)$. Out of 80 cases, abnormal neuroimaging is seen 60 cases $(75 \%)$ in which highest number of abnormal neuroimaging is seen in 5-9 years (41.7\%), followed by $30 \%$ in $9-13$ years. Normal neuroimaging is seen in $25 \%$ cases.

There is significant correlation seen between age and neuroimaging $(\mathrm{p}=<0.05)$ (Figure 2). Abnormal neuroimaging observed in $60(75 \%)$ patients out of total 80 patients. Abnormal neuroimaging observed in 37 patients (52.54\%), out of 51 patients with partial seizures. Abnormal neuroimaging observed in 23 patients, out of 29 patients with generalized seizures (Fig. 3). Highest number of abnormal neuroimaging are due to neurocysticercosis $48.8 \%(n=39)$, followed by tuberculoma $22.5 \%(n=18)$, CNS tumours $(n=2)$ namely medulloblastoma and astrocytoma, CNS malformation ( $\mathrm{n}=1$ ) namely porencephaly (Table 2 ).

Out of total 60 abnormal neuroimaging findings NCC are 39 , in which single lesions are seen in 34 cases, multiple $(>2$ in no) in 5 cases, 16 are calcified, 14 are non-calcified. Ring enhancement in 18 cases. Seizures were more on the right side; 3 cases were localized to the face. Seizures involving all the four limbs associated with loss of consciousness in 25 (31.3\%) cases. The MRI scan shows localization to the parietal lobe in $54 \%$ of these cases. Seizures were mainly single in number in 51 (53\%) cases and multiple $(>2)$ in number in $5(8.25 \%)$ cases. The associated symptoms were mainly headache in 25 (31\%) cases, vomiting in 22 (27.5\%) cases, loss of consciousness in $30(37.3 \%)$ cases, deviation of mouth in $63(78.6 \%)$ cases. Muscle weakness in 30 (31.2\%) cases and automatism in $4(5 \%)$ cases.

Patients presenting with 1st episode afebrile seizures showed very few clinical signs even after a thorough neurological examination, speech abnormality, dysarthria in $4(5 \%)$ cases, ptosis in $2(2.5 \%)$ cases, facial weakness in 12 $(15 \%)$ cases, raised ICT in $2(2.5 \%)$ cases. Papilloedema in 2 $(2.5 \%)$ cases. Only one case presented with status epilepticus, duration of convulsion mainly ranged from 10 to 15 minutes with the loss of consciousness from 1 to 2 hours. Signs of raised ICT was seen only in 2 cases. (Obstructive hydrocephalus + Bil. papilloedema). Immunization with BCG was given in total $60 \%$ cases; $60(75 \%)$ cases belong to grade I malnutrition, $15(18.75 \%)$ cases belong to grade II malnutrition, 5 (6.3\%) cases belong to grade III malnutrition.

Head circumference was appropriate for the age in all cases. CBP showed that 20 cases had eosinophilia, out of which neurocysticercosis was detected on neuroimaging in 6 cases and tuberculoma identified in 5 cases: remaining 9 cases had MRI scan normal study. ESR was raised in 6 cases.
Mantoux test was positive in 19 cases 6 cases showed ring enhancing, 1 showed an infarct and other had an obstructive hydrocephalus on MRI scan. There has been observed significant relation between Mantoux testing and neuroimaging $(p=<0.05)$. X-ray Chest: Only 2 cases had paratracheal haziness; 32 gave a history of eating pork. There is significant increase in ring enhancing lesions diagnosed as neurocysticercosis in pork eaters $(58.1 \%)(\mathrm{p}=0.02)$. Though cysticercosis has been reported to be higher among nonvegetarian people, especially pork eaters, many $(27 \%)$ of our patients were pure vegetarians, thereby supporting the fact that faeco-oral contamination is also a major route of the disease.
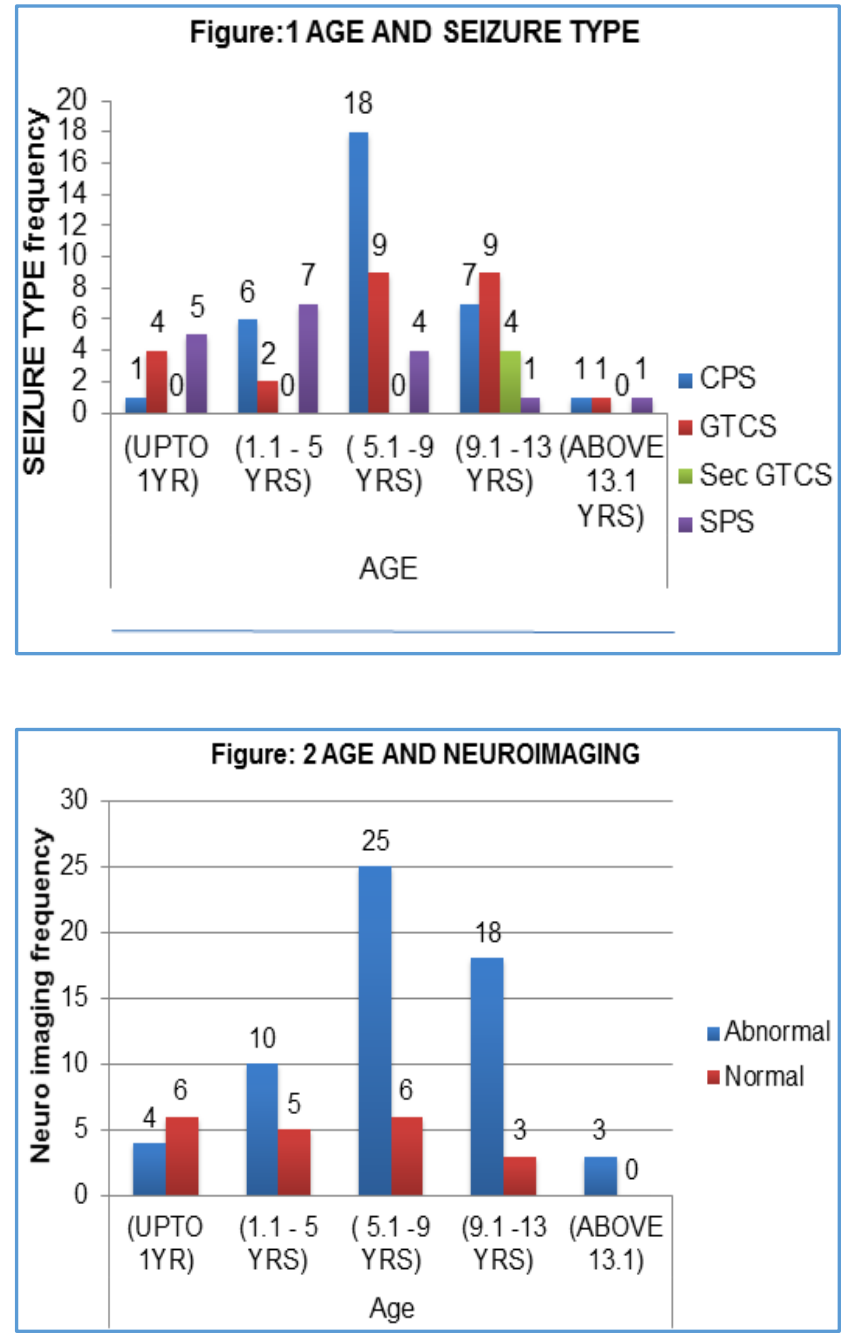

\begin{tabular}{|c|c|c|}
\hline Seizure Type & Frequency & Percent \\
\hline CPS & 33 & 41.3 \\
\hline GTCS & 25 & 31.3 \\
\hline Sec GTCS & 4 & 5.0 \\
\hline SPS & 18 & 22.5 \\
\hline Total & $\mathbf{8 0}$ & $\mathbf{1 0 0 . 0}$ \\
\hline \multicolumn{2}{|c}{ Table 1: Seizure Type Incidence } \\
\hline
\end{tabular}




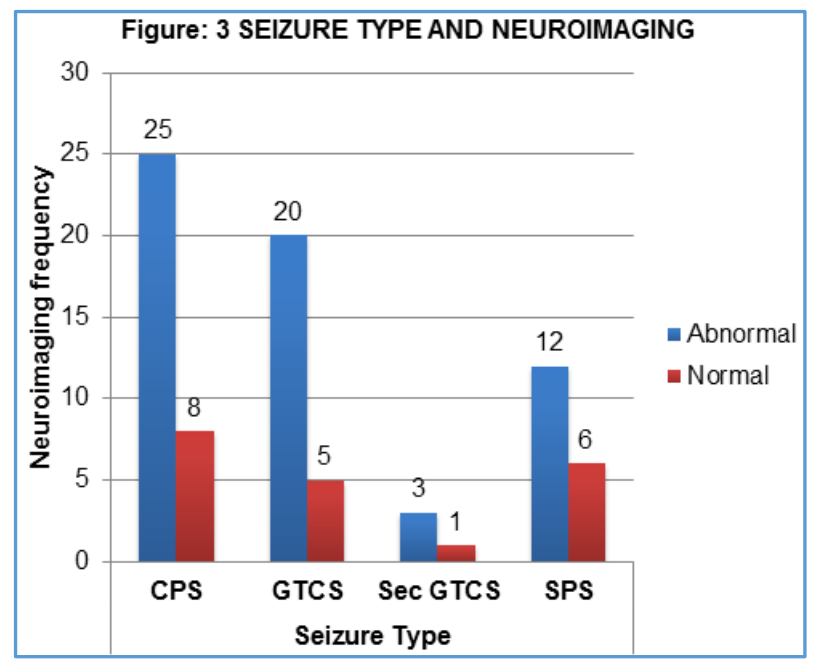

\begin{tabular}{|c|c|c|}
\hline $\begin{array}{c}\text { Neuroimaging } \\
\text { Findings }\end{array}$ & Frequency & Percent \\
\hline Astrocytoma & 1 & 1.3 \\
\hline Medulloblastoma & 1 & 1.3 \\
\hline NCC & 39 & 48.8 \\
\hline Normal & 20 & 25.0 \\
\hline Porencephaly & 1 & 1.3 \\
\hline Tuberculoma & 18 & 22.5 \\
\hline Total & $\mathbf{8 0}$ & $\mathbf{1 0 0 . 0}$ \\
\hline Table 2: Abnormal Neuroimaging Causes \\
\hline
\end{tabular}

\section{DISCUSSION}

Approximately, $4-6 \%$ of children are expected to have a seizure by the age of 16 years. The role of emergent neuroimaging for children with a new-onset afebrile seizure is not well understood; this is because the prevalence of neuroimaging abnormalities in this group has yet not been determined. However, regarding the results reported in the literature for adults, there has been a relatively high prevalence (Between 34-45\%) of CT scan abnormalities in adults with a new seizure. As a result, a recommendation has been published to perform neuroimaging in a large population of adults having their first seizure.(7) Practice parameters, which have been recently published recommend neuroimaging to be performed in a child of any age.(8) Our study enrolled 80 patients with their first afebrile seizure.

All patients with simple or complex febrile seizures as well as those with recurrent seizures were excluded. Neuroimaging was performed in 80 patients and abnormalities were found in $75 \%$ of cases and $25 \%$ were normal. The results showed that there was a significant relationship $(\mathrm{P}<0.05)$ between age and seizure type. In our study, most patients, i.e. $38.8 \%$ belong to age group of 5-9 years. This observation is in accordance with other studies done including all age groups, which states that the majority of the patients were below the age of 20 years. In our study, male sex (55\%) is more affected than female sex (45\%).

In a study conducted by Chaoshuang, et al from China found that the urban population is at a higher risk than the rural population.(9) Similar observations seen in urban populations in two Brazilian studies were $86.2 \%$ and $93.8 \%$, which showed urban population are at greater risk than rural population.(10),(11) In a study conducted by Rajshekhar et al, who studied active epilepsy as an index of burden of Neurocysticercosis in Vellore District, India, found that the prevalence in urban clusters was more than twice in the rural cluster (6.23 vs. 3.04 per 1000).(12) Contrast to the current literature and studies, our study has a high percentage of rural patients $(74 \%)$, probably related to poor hygienic conditions and higher amount of faecal contamination of drinking water in the rural areas. Cysticercosis is a disease of low socioeconomic conditions associated with poor hygiene and sanitation and poor safe drinking water. In a study conducted in Kerala, Kuruvilla et al found that $73 \%$ patients belonged to low socioeconomic category.(13) In similar two studies conducted from Chandigarh, $69 \%$ and $82.7 \%$ of the patients were of low socioeconomic strata.(14,15) Majority $(72.5 \%)$ of the cases in the our study were of lower socioeconomic class. Hence, our results are similar to other Indian studies.

The commonest MRI abnormality observed were Neurogranulomas was seen in $57(71.2 \%)$ cases in our studies. Shipra Mathur et al study conducted in North India, which showed prevalence of abnormal neuroimaging was $32 \%$, although our study result are greater than stated prevalence of Shipra Mathur et al.(16) Most common neuroimaging abnormality observed was NCC (49\%) followed by tuberculoma $(23 \%)$, which are similar to Shipra Mathur et al which was compatible with Sharma et al and Mayatal et al's studies.(17) In our study lesions were mainly single (53\%) and are more common than multiple lesions, which is agreeable with most other Indian studies. Most of them, 21 (36\%) had lesion localized to the parietal lobe with absent-to-moderate perilesional oedema. Parietal lobe has been found to be the most common site of single lesion neurocysticercosis.

\section{CONCLUSIONS}

Incidence of neuroimaging abnormality in children presenting with first afebrile seizure is high in developing countries like India, due to the high prevalence of neurocysticercosis and tuberculosis. So neuroimaging should be considered in any child with first afebrile seizure.

\section{REFERENCES}

1. McAbee GN, Walk JE. A practical approach to uncomplicated seizures in children. An Fam Physicians 2000;62(5):1109-16.

2. Newton CR, Garcia HH. Epilepsy in poor regions of the world. Lancet 2012;380(9848):1193-201.

3. Renzo Guerrini. Epilepsy in children. Lancet 2006;367(9509):499-524.

4. Sawhney IM, Singh A, Kaur P, et al. A case control study and one year follow up of registered epilepsy cases in a resettlement colony of North India, a developing tropical country. J Neurol Sci 1999;165(1):31-5.

5. Landfish N, Gieon-Korthals M, Weibley RE, et al. New onset childhood seizures. Emergency department experience. J Fla Med Assoc 1992;79(10):679-700.

6. Warden CR, Browstein DR, Del Baccaro MA. Predictors of abnormal findings of computed tomography of the head in paediatric patients presenting with seizures. Ann Emerg Med 1997;29(4):518-23.

7. American College of Emergency Physicians, American Academy of Neurology, American Association of Neurological Surgeons, American Society of Neuroradiology. Practice parameter: neuroimaging in the emergency patient presenting with seizure (Summary statement). Ann Emerg Med 1996;28(1):114-8. 
8. Practice parameter: evaluation of a first non-febrile seizure in children. Report of the quality standard subcommittee of the American academy of neurology, the child neurology and the American epilepsy Society. Neurology 2000;55:616-23.

9. Chaoshuang L, Zhixin Z, Xiaohongk W, et al. Clinical analysis of 52 cases of neurocysticercosis. Trop Doct 2008;38(3):192-4.

10. Das Chagas MG, D'OliveiraJúnior A, Tavares-Neto J. Clinical aspects of neurocysticercosis at semi-desert region of Brazilian northeast. Arq Neuropsiquiatr 2003;61(2B):398-402.

11. Benedeti MR, Falavigna DL, Falavigna-Guilherme AL, et al. Epidemiological and clinical profile of neurocysticercosis patients assisted by the hospital universitário regional de maringá, paraná, Brazil. Arq Neuropsiquiatr 2007;65(1):124-9.

12. Rajshekhar V, Raghava MV, Prabhakaran V, et al. Active epilepsy as an index of burden of neurocysticercosis in Vellore district, India. Neurology 2006;67(12):2135-9.
13. Kuruvilla A, Pandian JD, Nair $M$, et al. Neurocysticercosis: a clinical and radiological appraisal from Kerala State, South India. Singapore Med J 2001;42(7):297-303.

14. Baranwal AK, Singhi PD, Khandelwal N, et al. Albendazole therapy in children with focal seizures and single small enhancing computerized tomographic lesions: a randomized, placebo controlled, double blind trial. Paediatr Infect Dis J 1998;17(8):696-700.

15. Singhi P, Dayal D, Khandelwal N. One week versus four weeks of albendazole therapy for neurocysticercosis in children: a randomized, placebo controlled double blind trial. Pedi Infect Dis J 2003;22(3):268-72.

16. Shipra Mathur, Kevin Southern. Significant findings on cranial CT scan after a first unprovoked seizure in children from North India. J Trop Paediatr 2007;53(6):428-30.

17. Maytal J, Krauss JM, Novak G, et al. The role of brain computed tomography in children with seizures in the emergency department. Epilepsia 2000;41(8):950-4. 